УДК $159.98+37.015 .32$

\title{
СТРЕСС ИННОВАЦИЙ В ОБРАЗОВАНИИ
}

\author{
M. P. Арпентьева \\ Центр психологической, педагогической, медииинской и сочиальной помощи «Содействие» \\ Калуга, Российская Федераиия \\ e-mail: mariam_rav@mail.ru
}

\author{
К. М. Гайдар \\ Воронежский государственный университет \\ Воронеж, Российская Федерачия \\ e-mail:marlen_lora@mail.ru
}

\section{Л. А. Кунаковская}

Воронежский государственньй университет

Воронеж, Российская Федерачия

e-mail:kynludal@mail.ru

Аннотация. Данная статья посвящена стрессу инноващий в высшем и среднем образовании. Авторы обсуждают понятие стресса инноваций. Стресс инноваиий в учреждениях образования - стресс, который возникает в процессе и результате введения инноваций в образовании. Для студентов и преподавателей инновации - ситуачия, рождающая стрессы и постстрессовые нарушения (дидактогении в форме педиогений, матетогений и эдьюктогений). Инновации также выступают как способы преодоления таких стрессов, проблем и кризисов развития. Эти нарушения и попытки их преобразования касаются трансформаций и деформачий персонального, интерперсонального и организационного уровней. Важно отметить взаимосвязь причин и последствий, а также проявлений стрессов преподавателей и студентов на личностном, интерактивном, учебном и организационном уровнях. Основные иели исследования - выяснить, как стресс от инноваций в образовании воздействует на профессиональный и академический успех преподавателей и студентов и как он связан с их удовлетворенностью собой, своим здоровьем и жизнью в иелом. Основным методом исследования выступил теоретический анализ проблем стресса инноваиий у студентов и преподавателей в выстем образовании. Вместе с тем многие выводы были обобщены и распространены на среднее образование и образование в целом. Полученные результаты позволили заключить, что ученики (студенты) и учителя (преподаватели) нуждаются в обучении не только продуктивным и эффективнылм методам предотврашения и коррекции стресса инноваций / нововведений в ситуаџиях организационно-дидактического развития или, напротив, застоя в условиях реформ и других изменений, но и представлениям о возможностях, ограничениях, механизмах и направлениях развития в моменты кризисов и стрессов. Кризисные и стрессовые состояния психики ребенка и взрослого человека - это состояния, при которых возрастает риск формирования и закрепления девиантного поведения, нарушений развития, заболеваний и травм и т.д. Эти изменения становятся более выраженными в тех случаях, когда в условиях обучения и воспитания, работы и отдыха существуюшие и изменяющиеся отношения в проиеессе инноваций и другие изменения не принимаются во внимание. Все продуктивные и эффективные инновации в образовании связаны одной идеей - созданием условий, при которых развитие человека как личности, партнера и ученика / профессионала неизбежно, а не просто заявлено или невозможно. При разработке интегративной модели профилактики и преодоления стрессов инновачий для учащихся и преподавателей (при матетогениях, педиогениях и эдьюктогениях) важно поставить и решить задачи профилактики и коррекции стресса в контексте развития субъектов образования в разных контекстах: в контексте образовательного, профессионального, личностного и интерактивного развития. Профилактика и коррекция стресса в инновационном образовании (и в стрессе от инноваџий) связана с профилактикой и коррекцией педиогений (вреда, вызванного неправильным, разрушительнымм и патологизирующим отночением учителей к ученикам), матетогений (вреда, причиняемого неправильным, разрушительным и патологизирующим отношением учащихся к учителям) и эдьюктогений (вреда, связанного с деформащией организационных условий и форм обучения и воспитания). Один из компонентов 
работы - психологическая (психотерапевтическая) помощь субъектам образования (в форме разовых консультаций и тренингов, коучинга и систематического сопровождения). Такая помощь, даже в виде разовых консультаций, все же должна быть нацелена на системную, интегративную профилактику и коррекцию стрессов в образовании, включая стрессы инновации.

Ключевые слова: стресс, инноваџия, педиогения, матетогения, эдьюктогения, преодоление стресса, студенты, учителя, антикризисное управление, психологическая помощь.

Для цитаты: Арпентьева М.Р., Гайдар К. М., Кунаковская Л. А. Стресс инноваций в образовании // Профессиональное образование в современном мире. 2020. T. 10, №4. С. 4331-4346. DOI: https://doi.org /10.20913/2618-7515-2020-4-17

DOI: $10.20913 / 2618-7515-2020-4-17$

\title{
THE INNOVATION STRESS IN EDUCATION
}

\section{Arpentieva, M. R.}

Center for Psychological, Pedagogical, Medical and Social Assistance «Assistance»

Kaluga, Russian Federation

e-mail:mariam_rav@mail.ru

\section{Gaidar, K. M.}

Voronezh State University

Voronezh, Russian Federation

e-mail:marlen_lora@mail.ru

\section{Kunakovskaya, L. A.}

Voronezh State University

Voronezh, Russian Federation

e-mail:kynludal@mail.ru

\begin{abstract}
This article focuses on the stress of innovation in higher and secondary education. The authors discuss the concept of stress of innovation. The stress of innovation in educational institutions is the stress that occurs in the process and as a result of introducing innovations in education. Iinnovations for students and teachers are situations evoked stress and post-stress disorders (didactogeny in forms of pediogeny, mathetogeny and eductogeny). Innovation also acts as a way to overcome such stresses, problems, and development crises. These violations and attempts to transform them concern the transformations and deformations of personal, interpersonal, and organizational levels. It is important to note the relationship between causes and consequences, as well as the manifestations of stress of teachers and students at the personal, interactive, educational and organizational levels. The main study objectives are to find out how the stress of innovation in education affects the professional and academic success of teachers and students; and what way it relates to their satisfaction with themselves, their health and life in general. The main research method is a theoretical analysis of problems of the stress of innovation among students and teachers in higher education. At the same time, many conclusions were generalized and extended to secondary education and education in general. The obtained results made it possible to conclude that pupils (students) and teachers need both training in productive and effective methods of preventing and correcting the stress of innovation in situations of organizational and didactic development or, conversely, stagnation, in the context of reforms and other changes, and ideas about possibilities, limitations, mechanisms and directions of development in crisis and stress periods. Crisis and stress states of the child or adult psyche are conditions, which forming and fasten the risk of deviant behavior, developmental disorders, diseases and injuries, etc. These changes become more pronounced in cases, when under conditions of training and education, work and leisure existing and changing relationships in the process of innovation and other changes are not taken into account. All productive and effective innovations in education are connected by an idea-the creation of conditions under which the development of a man as a person, partner and student/professional is inevitable, and not just stated or impossible. While developing an integrative model to prevent and overcome the stress of innovation for students and teachers (in case of mathetogeny, pediogeny and eductogeny), it is important to set and solve the tasks of stress prevention and correction in the process of developing education subjects in
\end{abstract}


different contexts: educational, professional, personal and interactive development ones. Preventing and correcting education in innovative education (and the stress from innovation) is associated with the prevention and correction of pediogeneias (harm caused by the wrong, destructive and pathological attitude of teachers to students), mathetogenias (harm caused by the wrong, destructive and pathological attitude of students to teachers), and eductogenias (harm associated with the deformation of organizational conditions and forms of training and education). A component of this work is psychological (psychotherapeutic) assistance to the education subjects (in the form of one-time consultations and trainings, coaching and systematic support). Such assistance, even in the form of one-time consultations, should nevertheless be aimed at systematic, integrative prevention and correction of stresses in education, including the stresses of innovation.

Keywords: stress, innovation, pediogeny, mathetogeny, didactogeny, eductogeny, overcoming stress, teachers, students, crisis management, psychological assistance.

For quote: Arpentieva, M. R., Gaidar, K. M., Kunakovskaya, L. A. [The innovation stress in education]. Professional education in the modern world, 2020, vol. 10, no. 4, pp. 4331-4346. DOI: https://doi.org/10.20 913/2618-7515-2020-4-17

Введение. Исследование такой реальности, как стресс инноваций - задача и практически, и теоретически весьма значимая и актуальная. К большому сожалению, несмотря на многочисленность более чем полувековых отечественных и зарубежных, традиционных и современных исследований инноваций, их препятствий и трудностей, условий (не) успешности и (не) эффективности, а также исследований дидактогений и иных нарушений, возникающих в образовательном процессе [1-10], понятие стресса инноваций формулируется и раскрывается нами практически впервые. Мы развиваем понятие стресса инноваций, введенное М.Р. Арпентьевой для описания психологических процессов и эффектов, сопровождающих внедрение инноваций и последующее осмысление причин, процессов, результатов и последствий инноваций субъектами образовательной или иной организации $[11 ; 12]$. Стресс инноваций, если определить его кратко, - это стресс, который возникает в процессе и результате введения инноваций. Стресс инноваций в образовании - это стресс, который возникает у субъектов образования в процессе и результате введения инноваций.

Выраженность и важность учета стресса инноваций тем более значима, чем в большей степени речь идет об инновациях в сферах культурной трансмиссии, передачи и обмена опытом, в частности, в науке, искусстве, образовании. Еще одна сфера культурной трансмиссии и обмена людей опытом жизни - сфера массовых коммуникаций: ошеломляющее и непредсказуемое влияние инноваций в этой сфере хорошо демонстрирует «цифровая революция», дигитализация массовых коммуникаций, одним из результатов которой стала «приватизация массовости», кризис и вырождение традиционных СМИ, а также резкий качественно-количественный скачок - переориентация частных коммуникаций на коммуникации массовые (феномены «народной демократии», формирование и развитие практики чатов, сообществ, формирование и выделение в самостоятельную активность блогерской деятельности, сочетающей интимно-дневниковые и массовые формы жизнедеятельности личности, и т. д.). Инновации в образовании - связанные с такими феноменами и трендами как, дигитализация, метапредметность, инклюзивность и т. д., - еще более масштабны и по своим эффектам и последствиям будут оценены в полной мере еще не скоро. Однако результаты внедрения многих инноваций, как очевидно уже сейчас, просто огромны: об этом говорят метафоры типа «смерть университета», «непрерывное образование» и т. д. Как видно даже из этих метафор, перемены носят характер весьма неоднозначный: некоторые из инноваций помогают улучшить образование и отношения субъектов образования, но многие, напротив, его ухудшают и разрушают. Очевидно одно: для всех субъектов образования и остальных его стейкхолдеров инновации становятся стрессом, возникает стресс инноваций, воздействие которого на человека, группу / организацию и социум в целом как минимум двойственно (многосторонне, многоуровнево, многорезультативно).

Постановка задачи. Основная цель исследования - обоснование понятия стресса инновации в образовании.

Методология и методика исследования. Основным методом нашего исследования был теоретический анализ проблем осмысления инноваций студентами и преподавателями в высшем образовании. Вместе с тем многие выводы были обобщены и распространены на среднее образование и образование в целом.

Результаты. Основные результаты исследования. С середины XX в. наука о нововведениях в образовании и иных сферах на Западе стала сложной, разветвленной отраслью, но в СССР (России и иных 
Профессиональное образование в современном мире. 2020. Т. 10, № 4

Professional education in the modern world, 2020, vol. 10, no. 4

странах бывшего СССР) инновационные исследования только начали оформляться в самостоятельное направление научной деятельности. По мнению О.Г. Хомерики, М. М. Поташника, А. В. Лоренсова, педагогические инновационные процессы стали предметом специального изучения в СССР и постсоветских странах лишь в последние десятилетия ХХ в. [13]. Конечно, советская психология и педагогика 60-90-х гг. ХХ в. отнюдь не осталась в стороне от мирового инновационного поиска. Мы можем привести знаменитые инновационные поиски педагогов Минской и Ростовской областей, Татарстана, опыт педагогов-экспериментаторов С. И. Лысенковой, В. Ф. Шаталова, Е. Н. Ильина, И. П. Волкова, Л. В. Занкова, М.П. Кашина и др., этнопедагогические исследования и разработки педагогов многочисленных союзных республик СССР в целом. Однако в общем опыт рефлексивного научного исследования инноваций и их «проживания» школьниками и студентами, а также преподавателями вузов и школ был небольшим. В целом под инновацией понимается целенаправленное изменение системы отношений в организации в целях повышения качества деятельности человека или организации / социума [14; 15].

Теоретический анализ существующих современных и традиционных, зарубежных и отечественных исследований особенностей, содержания и процессов осмысления инноваций в образовательных и иных учреждениях показывает, что варианты такого осмысления и факторы, оказывающие влияние на инновации и их понимание членами образовательных и иных коллективов, весьма многообразны [16-22].

Также разнообразны сами реакции на стрессовые ситуации, варьирующиеся от легкого удивления новыми обстоятельствами и условиями взаимодействия и жизнедеятельности до системных кризисов, переворачивающих всю жизнь человека, порождающих не только временные, проходящие измененные состояния, но и более или менее стойкие и масштабные дисфункции и нарушения, способные привести человека к радикальным трансформациям, вплоть до гибели [23-25]. Кризисные и стрессовые состояния психики ребенка и взрослого - это состояния, при которых повышается риск формирования и закрепления отклоняющегося поведения, нарушений развития, болезней, травм и т. д. [26-30]. Они становятся более выраженными в тех случаях, когда в условиях обучения и воспитания, труда и отдыха не учитываются имеющиеся и изменяющиеся в процессе инноваций и иных перемен отношения. Они также становятся более заметными, когда нарушается соответствие между сложившимися и характерными для предыдущего этапа способами понимания себя и мира, характерными и нехарактерными традициями и принципами взаимоотношений с окружающими и развивающимися в течение этого периода возможностями и ограничениями человека как личности, партнера и ученика или профессионала. Расширение возможностей и преодоление ограничений деятельности ребенка и взрослого, включение их в новую систему отношений в целом могут весьма благоприятно сказываться на уровне физического, психического, социального и нравственного развития, создавая условия дальнейшего совершенствования и самосовершенствования. Однако не все перемены на самом деле новации, несущие смысл развития. Напротив, многие, особенно заданные извне перемены могут быть негативными. Только сами субъекты образования как стейкхолдеры и акторы могут найти те варианты консенсусных решений конфликтных, кризисных и стрессовых ситуаций, через которые они проходят. Только они могут понять причины и цели перемен, которые им дает жизнь. В ином варианте - типичном для образования многих стран современности, инновации в образовании есть плод метаний из одной крайности в другую, попытка исправить одни ошибки, делая другие. Исключение составляют, например, страны посткапитализма, например скандинавские, образование в которых, благодаря уважению государства к людям и уважению людей друг к другу, шагнуло недостижимо далеко для капиталистических, «развивающихся» стран и стран с «переходной» экономикой (бывшего СССР) вперед. Очевидно, что в этом контексте они действительно выполняют патологизирующую роль: пытаясь помочь в решении одних проблем, не только не достигают цели, но и создают новые проблемы и стрессы. В итоге в современной российской начальной, средней и даже высшей школе не только педагоги «вымещают» свою неудовлетворенность (неприятие, бессилие и невежество) на учениках, но и ученики и их семьи все чаще поступают так же. Пример - развернувшиеся в последние годы многочисленные и масштабные дискуссии в официальных и неофициальных СМИ и интернете по поводу того, что должны или не должны разрешать себе делать педагоги в своей повседневной жизни (что может квалифицироваться как шейминг и иные формы травли). Также сюда же можно отнести беспредметные по своему характеру, но порой весьма интенсивные дискуссии о том, кто должен заниматься детьми: школа или родители. Сюда же относятся и возникшие в последние десятилетия XX в. дискуссии о «ненужных предметах», «лишних требованиях», «перегруженности» учеников, рождающие требования снижения и так убогой, по сравнению с уровнем СССР середины ХХ в., нагрузки, к процедурной паритетности, к ученическому «самоуправлению» (которое выступает псевдоуправлением) в школах и вузах и т. д. Постановка дискутируемых вопросов часто говорит сама за себя: субъекты образования вместо участия в решении 
общих для них проблем, вместо решения задачи повышения качества образования заняты попытками ухода от решений, а в некоторых случаях и просто стремятся разрушить то немногое, что от образования еще осталось. Вдохновенные обсуждения «образовательных услуг» и непрерывного образования на фоне не менее вдохновенного утверждения «лоскутного сознания» современных учеников и прославления электронного обучения, иных «новаций», по сути разрушающих сам смысл образования, не путь к его развитию. Можно говорить о том, что некоторые «инновации» принадлежат не столько образованию, сколько деятельности по его подмене, то есть уничтожению. С продажей «образовательных услуг» это ясно настолько, насколько же понятен и восторг тех, кому эта подмена необходима. Очевидно, такие попытки - результат стрессов, деформировавших жизнь и сущность человека не только во время получения образования, но и помимо и задолго до того, как он был включен в образовательный процесс как ученик или педагог. Также очевидно, что эти попытки приводят к дальнейшим стрессам, формируя и усиливая масштаб и глубину разрушений в системе российского образования. Учителя и ученики, студенты и преподаватели вузов в итоге либо полностью (увольняясь, отказываясь от обучения), либо психологически (отчуждаясь, симулируя учебную или обучающую деятельность) уходят или даже изгоняются из образовательных учреждений, торгующих «образовательными услугами» вместо обучения и воспитания человека, члена сообщества, профессионала [9; 10 и др.]. Поскольку никаких выводов система образования в лице педагогического сообщества и администраций конкретных учреждений из происходящих перемен не делает, полагая проблемы каждого отдельного ученика и педагога их «личными делами» в рамках изменившего суть и формы образования госзаказа, данная тенденция все усиливается. Более того, симуляции в образовании порождают естественные процессы отторжения, отчуждения из этой сферы как педагогов-профессионалов, так и учеников, стремящихся к образованию. Администрация школ и вузов порой откровенно декларирует стремление избавиться от «неудобных», задающих вопросы о сути и качестве образования специалистов и учеников. Поощряются формы поведения не только снижающие внешний социальный статус профессионалов, но и уничтожающие его достоинство и самоуважение, полностью нивелирующие ценность педагогического труда и сакральные смыслы образования в целом. Эта тенденция приводит к закономерному дальнейшему сейчас уже тотальному регрессу системы образования. Напротив, уже упомянутая выше Скандинавская модель образования, опирающаяся на традиционные ценности и воспитывающая детей и юношество в атмосфере любви, уважения, интереса к себе и миру, и современное образование Великобритании, взявшейся восстанавливать оставшиеся осколки образования после «руин университета» с помощью методик советского образования (хотя и ради обеспечения своей стране состояния господства), есть две важных перемены:

1) сведены к минимуму беспредметные и популярные в современной России дискуссии о «гринфилдах» и «браунфилдах» («новых» и «старых» технологиях и методах образования), выбраны и организованы в единое целое действительно эффективные и продуктивные технологии и модели образования, нацеленные на помощь человеку в его становлении личностью, партнером и профессионалом;

2) подключены все заинтересованные акторы (субъекты образования) и иные стейкхолдеры (заинтересованные лица). Сами ученики и педагоги - как акторы - развивают себя как личностей, строят отношения, участия учить и учиться, - в атмосфере сотрудничества, уважения, служения, творческого поиска;

3) система ориентирована на традиционные ценности и обобщение богатства педагогического опыта всех поколений, всего человечества, но при сохранении максимальной открытости к осознанию и исправлению собственных ошибок, неточностей, преодолению дисфункций и барьеров отношений субъектов образования и иных стейкхолдеров.

Здесь уместно отметить, что многие современные ученые, говоря об инновациях, выделяют два типа обучения: «поддерживающее обучение» и «инновационное обучение». «Поддерживающее обучение» (maintainance learning) - процесс и результат такой учебной (а в результате и образовательной) деятельности, которая направлена на поддержание, воспроизводство существующей культуры, социального опыта, социальной системы. Такой тип обучения (и образования) обеспечивает преемственность социокультурного опыта, и именно он традиционно присущ как школьному, так и вузовскому обучению. «Инновационное обучение» (innovative learning) - процесс и результат такой учебной и образовательной деятельности, которая стимулирует вносить инновационные изменения в существующую культуру, социальную среду. Такой тип обучения (и образования), помимо поддержания существующих традиций, стимулирует активный отклик на возникающие как перед отдельным человеком, так и перед обществом проблемные ситуации. За рубежом учебный процесс сейчас часто рассматривается как самостоятельный поиск учащимися нового знания, новых познавательных ориентиров высокого уровня сложности (Э. де Боно, Д. Брунер, Э. де Корте, Д. Мезироу, М. Ноулз, Х. Таба, Д. Шваб и др.), процесс 
учебного исследования становится определяющим для построения обучения («процессуально-ориентированное» обучение) [31-33]. Однако при общем снижении планки образования «новое» знание все чаще является дискуссиями по поводу истинности наиболее банальных истин, а не действительными, открывающими мир и человека прозрениями.

Важно также отметить, что первый описанный теоретически тип обучения связан с ретрансляцией, воспроизводством социального опыта, второй - с творческим поиском на основе имеющегося опыта и тем самым с его обогащением. Однако практически невозможно найти такие формы образования, в которых практика обучения сводилась бы только к организации чистой репродукции, еще более нереально представить себе обучение на исключительно исследовательской основе. Скорее, дело в направленности обучения и поэтому в его нравственно-идеологических, социальных, психологических и иных условиях и результатах.

Репродуктивная и проблемная ориентации образовательного процесса воплощаются в двух основных инновационных подходах к преобразованию обучения в современной педагогике, технологическом и поисковом. Технологический подход модернизирует традиционное обучение на основе преобладающей репродуктивной деятельности учащихся, определяет разработку моделей обучения как организации достижения учащимися четко фиксированных эталонов усвоения. В рамках этого подхода учебный процесс ориентирован на традиционные дидактические задачи репродуктивного обучения, строится как «технологический», конвейерный процесс с четко фиксированными, детально описанными ожидаемыми результатами. Поисковый подход преобразует традиционное обучение на основе продуктивной деятельности учащихся, определяет разработку моделей обучения как инициируемого учащимися освоения нового опыта. В рамках этого подхода к обучению целью является развитие у учащихся возможностей самостоятельно осваивать новый опыт; ориентиром деятельности педагога и учащихся является порождение новых знаний, способов действий, личностных смыслов.

В этом контексте возможно видеть, что советская и российская школа педагогики и педагогической психологии внесла существенный вклад в мировую практику и теорию образования, что видно при анализе моделей образования в Японии, Скандинавии, Великобритании, образовании стран бывшего «социалистического лагеря» и т. д. Это происходило благодаря ориентации и советского, и российского образования на 1) многостороннюю и многоуровневую разработку методики образования, прекрасно представленной еще в дореволюционной России прошлого и позапрошлого веков; 2) создание развивающей, психологически безопасной и даже исцеляющей человека атмосферы (А.П. Макаренко, В.А. Сухомлинский и др.), на которую обратили особое внимание педагоги СССР; 3) гармонизацию отношений человека и сообщества, полноценное развитие всех субъектов; 4) ценностное и целостное осмысление обучения и воспитания человека на всех этапах его жизни, в контексте разных задач.

Как отмечала еще Л.А. Петровская [28], один из ведущих советских и российских психологов, существует несколько традиций образования, создающих в обучении и воспитании благоприятную, психотерапевтически воздействующую, то есть целительную атмосферу:

1) практико-ориентированный подход, дополняющий, а не заменяющий классический для советской школы, теоретически ориентированный, в том числе некоторые виды контекстного и проблемного образования;

2) деятельностно-смысловой подход, в том числе упомянутое выше контекстное, а также проблемное образование, некоторые виды программируемого образования и т. д.;

3) личностно-центрированный подход (опирающийся на идеи самореализации личности), в том числе модель образования-фасилитации или диалога, консультативно-ориентированная модель и т. д.

Все эти подходы связаны одной идеей - создания условий, в которых развитие человека как личности, партнера и профессионала неизбежно, а не просто декларируется или возможно. Важно, чтобы и инновационные, и традиционные методы и модели образования подходили ученику и педагогу, помогали им выстроить дидактическую коммуникацию, реализовав задачи обучения и воспитания без лишних деформаций. Создание условий развития человека опирается на идею преодоления ограничений, в том числе связанных с предшествующими стрессами образования и жизни, идею расширения возможностей человека и палитры его способов действия, совершенствования его отношений, включая конфликтную компетентность, умение учить и умение учиться, палитры способов продуктивного и эффективного совладания со стрессами, трудными и кризисными ситуациями внутри человека, в его отношениях с другими людьми и в учебно-профессиональной жизни. Создание условий развития человека также основывается на идее психологически безопасного, поддерживающего и подтверждающего сопровождения развития, в ходе которого человек обретает совершенство: полноту знаний и умений (ориентировочных основ), ясность и гармоничность целей и ценностей, транспарентность отношений с собой и людьми и т. д. В таких инновационных условиях стрессы образования или дидактогении 
(матетогении, педиогении, эдьюктогении) либо не возникают (превентируются), либо оперативно и полно корректируются. Конфликты как конфронтации ведут к развитию всех субъектов на всех уровнях. В иных ситуациях конфликты и стрессы подавляются и / или усиливаются. А инновации выступают как деструктивные перемены, ведущие к коллапсу образования и далее к деградации и уничтожению тех структур, которые создавали и внедряли эти инновации [34-39].

В целом, многие современные российские школьники и учителя средних и начальных школ, студенты и преподаватели вузов / колледжей нуждаются в психологической помощи, в том числе в консультировании по проблемам образовательных стрессов, по проблемам стрессов и кризисов развития, включая стрессы инноваций. Такая помощь должна быть направлена на системную, интегративную профилактику и коррекцию стрессов в образовании, включая стрессы инноваций в образовании.

Отношение людей, в том числе студентов и преподавателей, к нововведениям как таковым, не рассматривая их качественные показатели, различно. Одни люди склонны к их принятию, риску, ответственности и творчеству. Другие люди более консервативны, избегают риска, ответственности и перемен. Иногда в одном человеке одновременно уживаются различные проявления в отношении новаций из разных областей его деятельности. Для нас близка позиция, требующая учета качественной специфики изучаемой новации, которая, как уже отмечалось, может быть либо симулякром, либо псевдоновацией, направленной не на развитие, а на деструкцию образования и отношений субъектов образования.

В психологии имеется известная классификация субъектов инноваций, составленная Э. Роджерсом в теории диффузии инноваций (diffusion of innovation) [приводится по: 14; 15].

I группа - «новаторы», Innovators, обычно это около 2-3\% педагогического коллектива, которые почти всегда открыты новому, а порой просто «поглощены» новшествами. Они часто характеризуются некоторым авантюрным настроем, интенсивно общаются с локальными группами. Новаторы готовы рисковать, иметь самый высокий социальный статус, иметь финансовую ликвидность, социабельны и имеют самый близкий контакт с научными источниками и другими новаторами. Их толерантность к риску позволяет им применять технологии, которые в конечном итоге могут дать сбой. Финансовые и иные ресурсы помогают поглотить возможные неудачи.

II группа - «ранние реализаторы / последователи», Early adopters, их обычно около 13-14\%. Эти люди имеют высшую степень лидерства среди категорий новаторов. Ранние реализаторы имеют более высокий социальный статус, финансовую успешность, хорошее образование и более социально развиты, чем поздние. Они более осторожны в выборе, чем новаторы. Они используют разумный выбор стратегии реализации, чтобы помочь им сохранить центральную позицию в диалоге, интегрированы в некие местные объединения. Влиятельны, часто оказываются лидерами мнений.

III группа - раннее большинство, Early Majority, их обычно 34\%. Они принимают инновации через разное время, которое значительно дольше, чем инноваторы и ранние последователи. Раннее большинство имеет социальный статус выше среднего, контактирует с ранними последователями и редко занимает руководящие посты в системе.

IV группа - позднее большинство, Late Majority, их обычно 34\%. Относясь к новшествам со значительной долей скептицизма, приступают к их освоению иногда под давлением социальной среды, иногда в результате оценки собственных потребностей, но при одном условии: когда коллектив явно и однозначно высказывается в их пользу («средние реализаторы»). Они принимают инновации после среднего участника. Эти люди относятся к инновациям с высокой степенью скептицизма и после того, как большинство общества приняло инновации. Позднее большинство, как правило, скептически относятся к инновациям, имеют социальный статус ниже среднего.

V группа - отстающие или колеблющиеся, Laggards, их обычно порядка 16\%. Базовой характеристикой является ориентация на традиционные ценности. Они являются последними, чтобы принять новшество. В отличие от некоторых предыдущих категорий, люди в этой категории практически не демонстрируют лидерства. Эти люди обычно испытывают отвращение к агентам перемен. Отстающие, как правило, имеют тенденцию сосредотачиваться на «традициях», низком социальном статусе. Новшества принимают с большим трудом, это тормозящие агенты в распространении инноваций.

Для педагогов К. Ангеловски предлагает другие названия и характеристики выделенных Э. Роджерсом категорий: «новаторы», «передовики», «умеренные», «предпоследние», «последние» [14].

I категория - «новаторы» - включает преподавателей, открыто и решительно воспринимающих, внедряющих и распространяющих все новое, в том числе в своей собственной деятельности.

II категорию К. Ангеловски обозначает как «передовики»: в осмыслении новаций они занимают позицию впереди всех иных, поскольку полагают, что в актуальных социальных и образовательных обстоятельствах и условиях новшества нужно внедрять сразу же после их появления. 
III категория обозначена как «умеренная»: преподаватели этой группы не стремятся быть среди первых, но не стремятся остаться и среди последних, это золотая середина, которая признает новации, когда их признает большинство коллег и руководителей образовательных учреждений.

IV категория включает «предпоследних»: педагоги этой группы принимают новации в образовании практически последними.

$\mathrm{V}$ категория - «отстающие», они принимают новации позже других, руководствуясь принципом «Лучше поздно, но надежно».

Мы также можем ввести категорию VI - не принимающие новаций, традиционалисты. Однако дело в том, что человек может принимать одни и не принимать другие новации, чего ни в одной, ни в другой рассмотренной типологии не указано. Такой недифференцированный подход выхолащивает смысл изучения новаций и их «диффузий».

Полученные разными современными исследователями данные, включая наши собственные опросы и наблюдения, приводят к следующим выводам: около половины педагогов отличаются выраженным стремлением к новаторству (I и II категории), каждый пятый преподаватель находится в золотой середине; менее трети (30\%) относятся к нововведениям сдержанно (IV и V категории). При этом учителя наиболее часто применяют такие инновации, как изменение форм учебного контроля для отдельных учеников, развитие когнитивных и креативных качеств учеников, обучение без предварительного объяснения материала учителем (то есть самостоятельное изучение материала), рефлексия учениками и учителем своей деятельности. Категорически против нормотворчества самих учеников в образовании также около половины педагогов. Они против выбора учеником форм и методов его обучения и изменения целей учителя в угоду целям ученика (не менее четверти преподавателей). Не предполагают ориентироваться на публикацию ученических работ в научно-периодических изданиях как минимум треть педагогов. Не намереваются проводить занятия, направленные на развитие творческих способностей и стремлений учеников, как минимум четверть педагогов. Эвристическая образовательная ситуация не входит в предмет интереса и привычки также довольно значительной части учителей и преподавателей (от 20 до $60 \%$ в разных подгруппах).

У школьников и студентов результаты сходны. Так, около трети студентов отличаются выраженным стремлением к творчеству (I и II категории), много тех, кто находится в золотой середине, около трети относятся к нововведениям сдержанно (IV и V категории). При этом студенты часто приветствуют такие инновации, как изменение форм учебного контроля для отдельных учащихся и обучающихся, игровые и практические занятия, посвященные развитию их репродуктивных и креативно-творческих качеств, самостоятельное изучение материала; трудно развивается и воспринимается необходимость рефлексии учащимися, обучающимися и педагогами (учителями и преподавателями) своей деятельности. Они в большинстве случаев не против «нормотворчества», выбора учащимися и обучающимися форм и методов их обучения и изменения целей учителя / преподавателя в угоду целям учащихся и обучающихся. Не предполагают публиковать свои работы в периодических изданиях также весьма многие студенты: реально участвуют в этом процессе не более пятой части студентов, а чаще - порядка 1/10. В целом студентов привлекают занятия, нацеленные на пробуждение и развитие творческих способностей, но эвристическая образовательная ситуация вызывает у них: 1) вопросы и сомнения нужности (по большому счету, около половины вообще не понимает, что это и для чего), а также 2) трудности принятия (понимание творчества сужено до «авторской репродукции», творчеством субъективно признается все, что делает студент, вопреки объективным критериям). Многие преподаватели и исследователи по этому поводу отмечают, что студенты разучились и не имеют потребности мыслить, потребности познавать, причем они стремятся экономить на мышлении, запоминании и т. д. не только творческом, но и репродуктивном.

Имеющиеся на сегодня данные разных исследований свидетельствуют о том, что педагоги и студенты недостаточно готовы к принятию и реализации нововведений, что само по себе, вне дискуссии о качестве и направленности новаций и псевдоноваций, значительно снижает результативность вводимых в образовательный процесс новшеств. Одна из основных причин - пассивность и усталость как результат неверия в продуктивные и эффективные перемены, в которых человек сможет действительно проявить себя. Согласно Н.Ю. Посталюк, феномен готовности и способности к нововведениям - особое проявление творческого стиля деятельности человека как личности, партнера и ученика / профессионала [23]. В нем своеобразно сочетаются рефлексивность и антиконформизм, наличие индивидуального представления об образовании и стремление реализовать новые учебно-педагогические идеи, практические умения учить и учиться, в том числе применяя новые технологии. Этот аспект творческой учебно-педагогической деятельности можно условно назвать «вторичным творчеством», без которого не может быть в полной мере реализовано творчество «первичное» (идея, проект, теоретическое 
решение проблемы). Однако, по большому счету, здесь речь также идет об «авторской репродукции», о том, что педагог и его ученики могут стремиться к творчеству, но не быть способными и готовыми к нему.

Ученик, готовый и способный к инновациям, может быть охарактеризован следующими параметрами:

1) знаком со своими индивидуальными особенностями, чертами, возможностями и ограничениями, наиболее и наименее оптимальными темпоритмами и форматами учебных занятий по каждым из учебных предметов;

2) сформировал опыт реализации и развития своих творческих способностей в виде выполнения и обсуждения творческих / исследовательских / квалификационных работ, участия в индивидуальных и групповых творческих форумах, конкурсах, праздниках и иных мероприятиях;

3) осознает и способен разъяснить свои цели в обучении, в том числе цели занятий тем или иным учебным предметом, отчетливо понимая, зачем он ходит в школу / вуз и в чем себя реализует;

4) способен ставить учебную цель в конкретной области знаний или деятельности; разработать план ее достижения, а также выполнить план, осознать свой результат; сравнить его с аналогичными результатами других студентов; произвести рефлексию и самооценку своей деятельности;

5) обладает личностным пониманием смысла каждого из изучаемых предметов; владеет базовыми знаниями и умениями; ориентируется в основных учебных предметах, проблемах соответствующих наук, практик и искусств;

6) обладает высокими личностными результатами образования, отличающимися от общепринятых, в том числе от федеральных и региональных образовательных нормативов и стандартов;

7) способен и стремится обозначить свое понимание (или непонимание) по любым возникающим вопросам; умеет понять и оценить иную точку зрения, вести диалог, в том числе проблемный диалог (спор);

8) является носителем культурных норм и традиций, прожитых и усвоенных им; умеет аргументировать свои знания и объяснять умения, осмыслять полученные результаты;

9) способен и готов действовать в ситуациях выбора, вести себя спонтанно, и одновременно умеет выдерживать нормы поведения, которые задаются в школе / вузе и/или семье;

10) у него есть цель в жизни, он чувствует свою жизнь наполненной смыслом, умеет выстроить свои дальнейшие планы обучения на перспективу.

Педагог, готовый и способный к инновациям, характеризуется следующими параметрами:

1) способен и готов к учету индивидуального личностного потенциала учеников; выявляет личностные особенности учеников в каждой конкретной образовательной области;

2) уточняет фундаментальные образовательные объекты, связанные с ними проблемы и другие элементы образовательной программы личностно ориентированного типа;

3) отбирает культурные аналоги предполагаемым и уже продемонстрированным продуктам ученической образовательной деятельности;

4) организует и осмысляет психотехнологии продвижения учеников по их индивидуальным образовательным траекториям, способствует реализации индивидуального набора личностных качеств и ролей каждого ученика в обучении;

5) отмечает трансформации личностных, межличностных и образовательных качеств учеников и меру реализации их человеческого потенциала, исследуют образовательную продукцию учащихся (портфолио);

6) осуществляет сознательный анализ происходящего на основе мотивов и ценностей педагогической деятельности и общечеловеческих ценностей;

7) рефлексивно относится к педагогическим нормативам, рефлексирует и критически осмысляет происходящее, строит системы смыслов (смыслотворчество);

8) открыт среде и профессиональным новшествам и творчески преобразующе относится к миру, выходит за пределы нормативной заданности;

9) имеет стремление к самореализации, воплощению в профессиональной деятельности своих намерений и образа жизни;

10) наполняет элементы учебного материала и форм его подачи личностным смыслом, конкретен в общении с людьми.

Одним из недостатков педагогики высшей школы является то, что процесс становления будущего педагога не моделирует структуру инновационной деятельности. Целенаправленного изучения педагогической инноватики в действующих образовательных стандартах высшего профессионального образования не предусмотрено. Студентов также в лучшем случае ориентируют на творческий подход, что позволяет им понимать идею, но не технику той или иной инновационной разработки. Такое положение дел не способствует развитию инновационного образования. Поэтому возникла необходимость в специальной системе подготовки педагогов и учеников к инновационной деятельности. Такая 
Профессиональное образование в современном мире. 2020. Т. 10, №4

Professional education in the modern world, 2020, vol. 10, no. 4

подготовка - один из компонентов профилактики и коррекции стрессовых состояний, связанных с нарушениями и изменениями дидактического взаимодействия.

Крайне важно отметить: само по себе нарушение дидактического взаимодействия для возникновения дидактогении не обязательно, достаточно неготовности и неспособности к переменам у студентов и преподавателей [15-17].

В контексте подготовки к инновационной деятельности В.А. Сластёнин и Л. С. Подымова описали поэтапную схему подготовки будущего учителя к инновационной деятельности [24].

I этап - поддержка творческой индивидуальности педагога, развитие у студентов способности и стремления изучать мир и ставить вопросы, разрешать творческие учебно-педагогические задачи, совершенствование технологий творческого поиска: самостоятельный перенос ранее присвоенных знаний и умений в новые контексты, усмотрение новизны и проблем в кажущейся знакомой ситуации, освоение новой функции объекта, переопределение его структуры, осмысление альтернатив решения или его способа, рекомбинирование ранее присвоенных способов деятельности с новыми в контексте возникших проблем или целей деятельности, развитие рефлексивности в понимании себя и мира. II этап - овладение базисными аспектами методологии научного познания, в том числе педагогического исследования, постижение основ инновационной педагогики. Студенты знакомятся с социальными и научными условиями развития инновационной педагогики, ее базисными терминами и концептами, творчески реинтерпретируют альтернативные подходы к (ре) организации школ и вузов, исследуют главные истоки становления и совершенствования альтернативной школы, получают представление о разных видах инновационных учебных программ и заведений и т. д. III этап - присвоения технологии инновационной деятельности. Студенты знакомятся с методикой составления авторских программ, этапами экспериментальной работы в школах и вузах, соучаствуют в создании и апробации авторских программ - с преподавателем и иными студентами, анализируют и прогнозируют дальнейшее развитие новшества, трудности внедрения. IV этап - конкретно-практическая работа на экспериментальных площадках по введению инноваций в образовании, производство коррекции, осмысление процессов и результатов эксперимента, учебной и профессиональной деятельности. Формируется инновационная позиция педагога как система ценностей и отношений к инновациям.

Такое построение учебного процесса способствует разрешению проблемы подготовки учителя к инновационной педагогической деятельности, а учеников - к инновациям в обучении.

Реакция человека на «навязывание» ему нововведения, как правило, проходит несколько фаз, например: отрицание, сопротивление, исследование, вовлеченность, традиционализацию [5; 6; 25; 26]. Фаза отрицания может быть характерна для подчиненного состоянием шока, растерянности. Здесь еще происходит ориентация на прошлое. В первой фазе отрицательную роль часто играет недостаточная информированность педагогического коллектива или учеников о характере нововведения, поэтому целесообразно, игнорируя проявление недовольства, ориентировать людей на будущее, давая им время для адаптации. В фазе сопротивления возможно проявление педагогами и студентами раздражения, возникновение у них депрессии, связанной с ощущением неизбежности перемен. Здесь нужно наладить обратную связь с коллективом, больше слушать, поддерживать колеблющихся. Но порой целесообразным может быть и резкая конфронтация с предложением сделать выбор. В фазе исследования человек, согласившись с неизбежностью перемен, начинает ориентироваться в новых формах деятельности. В этот момент необходимо следить за процессом, поддерживать его динамику, из обилия идей выделить приоритеты. В фазе вовлеченности характерно возникновение творческих групп. Постановка целей становится более точной. Резко улучшается координация деятельности. На этом этапе необходимо совместно разрабатывать долгосрочные цели и ритуалы новой повседневности (новые образовательные «рутины»).

Важно также отметить момент, связанный с созданием целостной, многоуровневой и многоаспектной, продуманной и грамотно выстроенной среды непрерывного (продолжающегося) образования. Дело не только и не столько в том, что человеку могут пригодиться знания и умения в разных сферах и разного уровня, не только в том, что судьба может побудить его сменить профессию, семью, место жительства и т. д.: от этого не застрахован человек ни одной эпохи и ни одной культуры. Дело в том, что само по себе развитие человека как личности, партнера и профессионала побуждает его к приобретению знаний и освоению умений в самых разных сферах, начиная от общеобразовательного «максимума», дающего возможность стать субъектом культуры, и заканчивая знаниями и умениями в сфере профессиональных, семейных и т. д. отношений и видов деятельности. Не случайно возникают понятия «компетентное родительство» и т. п.: вопреки доктринам насильственного сужения спектра знаний и умений, которые (ре) транслируются будущим поколениям в России и иных странах, нарастает и тенденция расширения представлений о спектре необходимых человеку знаний и умений, нужных ему, чтобы быть личностью, партнером и профессионалом. Это касается и основного, и дополнительного 
образования, в том числе того, которое направлено на осмысление себя существом планетарным и космическим [40-47].

Выводы. Заключение. Стресс инноваций - это стресс, который возникает в процессе и результате введения инноваций. Для школьников и учителей, студентов и преподавателей инновации являются как ситуацией, порождающей стрессы и кризисы персонального, интерперсонального и организационного уровней, так и способом преодоления таких стрессов, проблем и кризисов развития. Важно отметить взаимосвязь причин и последствий, а также проявлений стрессов преподавателей и студентов на личностном, интерактивном, учебном и организационном уровнях. Ученики (школьники и студенты) и педагоги (учителя и преподаватели) нуждаются не только в обучении продуктивным и эффективным методам предотвращения и коррекции стресса нововведений в ситуациях организационно-дидактического развития и застоя, реформ и других изменений.

Кризисные и стрессовые состояния психики ребенка и взрослого человека - это состояния, при которых возрастает риск формирования и закрепления девиантного поведения, нарушений развития, заболеваний и травм и т. д. Эти изменения становятся более выраженными в тех случаях, когда в условиях обучения и воспитания, работы и отдыха существующие и изменяющиеся отношения в процессе инноваций и другие изменения не принимаются во внимание. Все продуктивные и эффективные инновации в образовании связаны одной идеей - созданием условий, при которых развитие человека как личности, партнера и профессионала неизбежно, а не просто заявлено или невозможно.

В ходе разработки целостной модели профилактики и преодоления стресса для учащихся и преподавателей (при матетогениях, педиогениях и эдьюктогениях) важно ставить задачи профилактики и коррекции стресса в контексте развития субъектов образования в разных контекстах: в контексте образовательного, профессионального, личностного и интерактивного развития. Профилактика и коррекция стресса в инновационном образовании (в контексте профилактики и коррекции стресса инноваций) связана с профилактикой и коррекцией дидактогений:

1) педиогений (вреда, вызванного неправильным, разрушительным и патологизирующим отношением учителей к ученикам);

2) матетогений (вреда, причиняемого неправильным, разрушительным и патологизирующим отношением учащихся к учителям);

3) эдьюктогений (вреда, связанного с деформацией организационных условий и форм обучения и воспитания).

Важные компоненты такой работы - направленная превентивно-профилактическая, экспертно-диагностическая, посредническая (медиационная), коррекционно-воспитательная, развивающая, направленная на поддержку становления и самосовершенствования помощь субъектам образования. Один из компонентов работы - психологическая (психотерапевтическая) помощь субъектам образования (в форме разовых консультаций и тренингов, медиаций и посредничества, коучинга и систематического сопровождения). Такая помощь, даже в виде разовых консультаций, все же должна быть нацелена на системную, интегративную профилактику и коррекцию стрессов в образовании, включая стрессы инновации. Такая помощь должна быть направлена на развитие субъектов образования и социума в целом в контексте их становления личностями, партнерами, учениками и профессионалами.

\section{СПИСОК ЛИТЕРАТУРЫ}

1. Авакян И.Б., Виноградова Г.А. Оценка инновационной готовности педагогических коллективов вузов // Психолого-педагогические исследования. 2020. Т. 12, №1. С. 16-30. DOI: $10.17759 /$ psyedu.2 020120102.

2. Авксененко Т.Н. Влияние школьных дидактогений на социально-психологическую адаптацию студентов // Вестник университета. 2014. № 15. С. 219-222.

3. Загвязинский В.И., Строкова Т. А. Сопротивление инновациям: сущность, способы профилактики и преодоления // Образование и наука. 2014. №3. С. 3-21.

4. Мирошниченко А. А. Комплексная оценка деятельности учителя как условие профилактики дидактогении // Вопросы психического здоровья детей и подростков. 2017. Т. 17, № S2. C. 162-163.

5. Наумцева Ю. Психологическая готовность к организационным изменениям: подходы, понятия, методы // Организационная психология. 2016. Т. 6, №2. С. 55-74.

6. Панферов В.Н., Безгодова С.А., Васильева С.В., Иванов А.С., Микляева А. В. Эффективность обучения и академическая мотивация студентов в условиях онлайн-взаимодействия с преподавателем (на примере видеолекции) // Социальная психология и общество. 2020. Т. 11, № 1. С. 127 143. DOI: $10.17759 /$ sps.2020110108. 
7. Пуляева В.Н., Неврюев А.Н. Взаимосвязь базовых психологических потребностей, академической мотивации и отчуждения от учебы обучающихся в системе высшего образования // Психологическая наука и образование. 2020. Т. 25, №2. С. 19-32. DOI: 10.17759/pse.2020250202.

8. Шарыпова Т.Н., Забейворота М.В. Социально-психологические и профессиональные риски психологического «выгорания», как фактор возникновения внутриличностного конфликта // Аллея науки. 2019. Т. 2, №3. С. 237-241.

9. Hascher T., Hadjar A. School alienation - Theoretical approaches and educational research // Educational Research. 2018. Vol. 60, №2. P. 171-188. DOI: 10.1080/00131881.2018.1443021.

10. Pampaka M., Pepin B., Sikko S.A. Supporting or alienating students during their transition to higher education: mathematically relevant trajectories in the contexts of England and Norway // International Journal of Educational Research. 2016. Vol. 79. P. 240-257. DOI: 10.1016/j.ijer.2016.06.008.

11. Kassymova G.K., Tokar O.V., Tashcheva A.I., Slepukhina G.V., Gridneva S.V., Bazhenova N.G., Shpakovskaya E. Yu., Arpentieva M. R. Impact of stress on creative human resources and psychological counseling in crises // International Journal of Education and Information Technologies. 2019. Vol. 13, №1. P. 26-32.

12. Kassymova K. G., Tyumaseva Z. I., Valeeva G. V., Lavrinenko S. V., Arpentieva M. R., Kenzhaliyev B. K., Kosherbayeva A. N., Kosov A. V., Duvalina O. N. Integrative model of student and teacher stress coping: the correction of relations in educational, professional and personal interaction // Bulletin of National Academy of Sciences of the Republic of Kazakhstan. 2019. Vol. 3, № 379. P. 2-11. DOI: https:// doi.org/10.32 014/2019.2518-1467.53.

13. Хомерики О. Г., Поташник М.М., Лоренсов А. В. Развитие школы как инновационный. Москва: Новая школа, 1994. 62 с.

14. Ангеловский К. Учителя и инновации: кн. для учителя. Москва: Просвещение, 1991. 159 с.

15. Rogers E. M. Diffusion of innovations. New York: Simon and Schuster, 2003. 340 p.

16. Еременко С. А., Попова В. В. Роль психологического консультирования при коррекции профессионального выгорания работников социальной сферы // Вестник Иркутского университета. 2019. № 22. C. 78-79.

17. Загашев И.О. Психологические аспекты готовности к инновациям у преподавателей высшей школы и качество управления инновациями // Вестник Санкт-Петербургской государственной медицинской академии им. И. И. Мечникова. 2008. №2. С. 105-107.

18. Зимняя И.А. Компетентностный подход. Каково его место в системе современных подходов к проблемам образования // Высшее образование сегодня. 2006. №8. С. 20-27.

19. Кларин М.В. Инновации в мировой педагогике: обучение на основе исследования, игр, дискуссии. Москва: Эксперимент, 1995. 176 с.

20. Остапенко А. А., Хагуров Т. А. Образовательные инновации и реформы глазами учителей и преподавателей. Краткий обзор социологического исследования // Международный журнал экспериментального образования. 2013. №4. Р. 221-226.

21. Khatri R., Henderson C., Cole R., Froyd J.E., Friedrichsen D., Stanford C. Characteristics of wellpropagated teaching innovations in undergraduate STEM // International Journal of STEM Education. 2017. Vol. 4, art. 2. P. 1-10. DOI: http://dx.doi.org/10.1186/s40 594-017-0056-5.

22. Ranga M., Etzkowitz H. Triple Helix systems: an analytical framework for innovation policy and practice in the knowledge society // Entrepreneurship and knowledge exchange. New York, 2015. P. 117-158. DOI: http://dx.doi.org/10.4324/9781315795638.

23. Rerke V.I., Bubnova I.S., Tatarinova L.V., Zhigalova O.V., Gordina O.V., Gordin A.I. Motivational readiness of teachers to innovate in educational organization: psychological aspect // Revista Espacios. 2019. Vol. 40, № 26. P. 1-7.

24. Посталюк Н.Ю. Творческий стиль деятельности: педагогический аспект. Казань: Изд-во Казанского ун-та, 1989. 205 с.

25. Сластенин В.А., Подымова Л.С. Педагогика: инновационная деятельность. Москва: Магистр, 1997. $224 \mathrm{c}$.

26. Платонова Н.М., Платонов М. Ю. Современные тенденции развития высшей школы // Ученые записки Санкт-Петербургского государственного института психологии и социальной работы. 2014. № 1. С. 81-86.

27. Ушаков К.М. От отрицания до вовлеченности. Модель поведения администратора, внедряющего инновации // Директор школы. 1996. №5. С. 3-6.

28. Стрюкова Г.А. Профилактика профессионального выгорания: психологическое просвещение педагогов по проблемам самоактуализации // Мир науки. Педагогика и психология. 2019. Т. 7, №6. С. 1-3. 
29. Минигалиева М.Р. Изучение психологии и самопознания студентов. Психотерапевтическая модель педагогического общения. Саарбрюккен: LAP, 2012. 632 с.

30. Herlofsen P. Group treatment in the aftermath of trauma // Balliere»s Clinical Psychiatry. 1996. Vol. 2. P. 315-328.

31. Jonker J. Toolbook for organizational change. A practical approach for managers. London: Van Gorcum and Comp BV, 1995. 260 p.

32. Брунер Дж. Процесс обучения пересмотрен // Phi Delta Каppa. 1971. Вып. 53, № 1. C.18-21.

33. Кларк Б. Р. Поддержание изменений в университетах. Преемственность кейс-стади и концепций. Москва: Изд. дом Высш. шк. экономики. 2011. 312 с.

34. Bruner J. S. Toward a theory of instruction. Cambridge: Cambridge Univ. Press, 1966. 156 p.

35. Гайдар К.М., Малютина О.П. Особенности профессионального выгорания преподавателя высшей школы в современных условиях // Вестник Воронежского государственного университета. Серия: Проблемы высшего образования. 2016. №2. С. 27-30.

36. Кунаковская Л. А. Деструктивные проявления в профессиональной деятельности преподавателя вуза // Преподаватель ХХІ век. 2016. №2. С. 78-82.

37. Кунаковская Л.А., Охрименко Т.В. Психолого-педагогическая подготовка сотрудников службы «Няня на час» к взаимодействию с дошкольниками и младшими школьниками // Известия Воронежского государственного педагогического университета. 2014. Т. 262, №1. С. 116-119.

38. Кунаковская Л. А. Самосовершенствование педагога высшей школы // Педагогическая образование и наука. 2014. №6. С. 89-93.

39. Кунаковская Л.А. Профессиональная рефлексия как фактор самосовершенствования педагога. Воронеж: ЦНТИ, 2015. 204 с.

40. Anderson T., Varnhagen S., Campbell K. Faculty adoption of teaching and learning technologies: contrasting earlier adopters and mainstream faculty // The Canadian Journal of Higher Education. 1998. Vol. 28, № 23. P. 71-78.

41. Kassymova G. K., Stepanova G. A., Stepanova O. P., Menshikov P. V., Arpentieva M. R., MerezhnikovA.P., Kunakovskaya L.A. Self-development management in educational globalization // International Journal of Education and Information Technologies. 2018. Vol. 12, № 12. Р. 171-176.

42. Ключарев Г. А., Дежина И.Г. Российское образование для инновационной экономики: «болевые точки» // Социологические исследования. 2018. №9. С. 40-48.

43. Perikova E. I., Atamanova I. V., Bogomaz S. A. Specific features of psychological readiness for innovative activity (with the main focus on young adults in St. Petersburg and Tomsk) // Science for Education Today. 2020. Vol. 10, №. 1. P. 62-78. DOI: http://dx.doi.org/10.15293/2658-6762.2001.04.

44. Stock R. M., von Hippel E., Gillert N. L. Impacts of personality traits on consumer innovation success // Research Policy. 2016. Vol. 45, №4. P. 757-769. DOI: https://doi.org/10.1016/j.respol.2015.12.002.

45. Sutanto E.M. The influence of organizational learning capability and organizational creativity on organizational innovation of Universities in East Java, Indonesia // Asia Pacific Management Review. 2017. Vol. 22. P. 128-135. DOI: 10.1016/j.apmrv. 2016.11.002.

46. Tenzer H., Yang P. Personality, Values, or attitudes? Individual-level antecedents to creative deviance // International Journal of Innovation Management. 2019. Vol. 23, №2. P. 1-30. DOI: http://dx.doi.org/10.1142/S1363919619500099.

47. Walder A. M. Pedagogical Innovation in Canadian higher education: professors' perspectives on its effects on teaching and learning // Studies in Educational Evaluation. 2017. Vol. 54. P. 71-82. DOI: 10.1016/j.stueduc.2016.11.001.

48. Weitze C.L. Designing pedagogical innovation for collaborating teacher teams // Journal of Education for Teaching. 2017. Vol. 43, №3. P. 361-373. DOI: 10.1080/02607476.2017.1319511.

\section{REFERENCES}

1. Avakyan I.B., Vinogradova G.A. Evaluation of innovative readiness of teaching staff of universities. Psychologic-Pedagogical Studies, 2020, vol. 12, no. 1, pp. 16-30. DOI: 10.17759/psyedu.2020120102. (In Russ.)

2. Avksenenko T.N. Influence of school didactogenies on socio-psychological adaptation of students. niversity Herald, 2014, no. 15, pp. 219-222. (In Russ.)

3. Zagvyazinsky V.I., Strokova T.A. Opposition to innovations: essence, methods of prevention and overcoming. Education and science, 2014, no. 3, pp. 3-21. (In Russ.)

4. Miroshnichenko A.A. Comprehensive evaluation of teacher's activity as a condition to prevent didactogeny. Mental health issues for children and adolescents, 2017, vol. 17, no. S2, pp. 162-163. (In Russ.) 
5. Naumtseva Y. Psychological readiness for organizational change: approaches, concepts, methods. Organizational Psychology, 2016, vol. 6, no 2, pp. 55-74. (In Russ.)

6. Panferov V.N., Bezgodova S.A., Vasil'yeva S. V., Ivanov A.S., Miklyayeva A.V. Learning efficiency and academic motivation of students in online interaction with a teacher (using a video lecture case). Social Psychology and Society, 2020, vol. 11, no. 1, pp. 127-143. DOI: 10.17759/sps.2 020110108 . (In Russ.)

7. Pulyaeva V.N., Nevryuev A.N. Interrelation of basic psychological needs, academic motivation and alienation from students studying in higher education. Psychological Science and Education, 2020, vol. 25, no. 2, pp. 19-32. DOI: 10.17759 / pse.2020250202. (In Russ.)

8. Sharypova T. N., Zabeyvorota M.V. Socio-psychological and professional risks of psychological «burnout» as a factor in an intrapersonal conflict occurrence. Alley of science, 2019, vol. 2, no. 3, pp. 237-241. (In Russ.)

9. Hascher T., Hadjar A. School alienation - theoretical approaches and educational research. Educational Research, 2018, vol. 60, no. 2, pp. 171-188. DOI: 10.1080/00131881.2018.1443021.

10. Pampaka M., Pepin B., Sikko S.A. Supporting or alienating students during their transition to higher education: mathematically relevant trajectories in the contexts of England and Norway. International Journal of Educational Research, 2016, vol. 79, pp. 240-257. DOI: 10.1016/j.ijer.2016.06.008.

11. Kassymova G.K., Tokar O.V., Tashcheva A.I., Slepukhina G.V., Gridneva S.V., Bazhenova N. G., Shpakovskaya E. Yu., Arpentieva M. R. Impact of stress on creative human resources and psychological counseling in crises. International Journal of Education and Information Technologies, 2019, vol. 13, no. 1, pp. 26-32.

12. Kassymova K. G., Tyumaseva Z.I., Valeeva G.V., Lavrinenko S. V. Arpentieva M.R., Kenzhaliyev B. K, Kosherbayeva A. N., Kosov A. V., Duvalina O.N. Integrative model of student and teacher stress coping: the correction of relations in educational, professional and personal interaction. Bulletin of National Academy of Sciences of the Republic of Kazakhstan, 2019, vol. 3, no. 379, pp. 2-11. DOI: https://doi.org/10.32014/2019.2518-1467.53.

13. Khomeriki O.G., Potashnik M. M., Lorensov A. V. School development as an innovative process. Moscow, New School, 1994, 61 p. (In Russ.)

14. Angelovski K. Teachers and innovations: book for teacher. Moscow, Education, 1991, 159 p. (In Russ.)

15. Rogers E. M. Diffusion of innovations. New York: Simon and Schuster, 2003, 340 p.

16. Eremenko S.A., Popova V.V. The role of psychological counseling in the correction of professional burnout of social workers. Bulletin of Irkutsk University, 2019, no. 22, pp. 78-79. (In Russ.)

17. Zagashev I.O. Psychological readiness for innovation as a condition of effectiveness of implementing quality management systems. Bulletin of I. I. Mechnikov St. Petersburg State Medical Academy, 2008, no. 2, pp. 105-107. (In Russ.)

18. Zimnyaya I.A. A competence approach. What is its place in the system of the modern approaches to education problems. Higher education today, 2006, vol. 4, pp. 20-27. (In Russ.)

19. Clarin M. V. Innovations in world pedagogy: training based on research, games, discussions. Moscow, Experiment, 1995, 176 p. (In Russ.)

20. Ostapenko A.A., Khagurov T.A. Educational innovations and reforms through the eyes of teachers and teachers: a brief survey of sociological research. International Journal of Experimental Education, 2013, no. 4, pp. 221-226. (In Russ.)

21. Khatri R., Henderson C., Cole R., Froyd J. E., Friedrichsen D., Stanford C. () Characteristics of well-propagated teaching innovations in undergraduate STEM. International Journal of STEM Education. 2017, Vol. 4, art. 2, pp. 1-10. DOI: http://dx.doi.org/10.1186/s40 594-017-0056-5.

22. Ranga M., Etzkowitz H. Triple Helix systems: an analytical framework for innovation policy and practice in the knowledge society. Entrepreneurship and knowledge exchange. Routledge, New York, 2015, pp. 117-158. DOI: http://dx.doi.org/10.4324/9781315795638.

23. Rerke V.I., Bubnova I. S., Tatarinova L.V., Zhigalova O. V., Gordina O. V., Gordin A. I. Motivational readiness of teachers to innovate in educational organization: psychological aspect. Revista Espacios, 2019, vol. 40, no. 26, pp. 1-7.

24. Postalyuk N. Yu. Creative style of activity: pedagogical aspect. Kazan, Kazan Univ. Publ., 1989, 205 p. (In Russ.)

25. Slastenin V.A., Podymova L. S. Pedagogy: innovative activity. Moscow, Magister, 1997, 224 p. (In Russ.)

26. Platonova N.M., Platonov M. Yu. Modern trends in the higher education development. Scientific notes of Saint-Petersburg State Institute of Psychology and Social Work, 2014, no. 1, pp. 81-86. (In Russ.)

27. Ushakov K. M. From denial to involvement. A behavior model of administrator introducing innovations. School Director, 1996, no. 5, pp. 3-6. (In Russ.) 
28. Stryukova G.A. Prevention of professional burnout: psychological education of teachers on the issues of self-actualization. World of Science. Pedagogy and psychology, 2019, vol. 6, no. 7, pp. 1-3. (In Russ.)

29. Minigalieva M. R. The study of psychology and self-knowledge of students. Psychotherapeutic model of pedagogical communication. Saarbrucken, LAP, 2012, 632 p. (In Russ.)

30. Herlofsen P. Group treatment in the aftermath of trauma. Balliere's Clinical Psychiatry, 1996, vol. 2, pp. 315-328.

31. Jonker J. Tool-book for organizational change. A practical approach for managers. London, Van Gorcum a. Comp BV, 260 p.

32. Bruner J. S. Process of education reconsidered. Phi Delta Kappan, 1971, vol. 53, no. 1, pp. 18-21. (In Russ.)

33. Clark B. R. Maintaining change at universities. The succession of case studies and concepts. Moscow, Higher School of Economics Publ., 2011, 312 p. (In Russ.)

34. Bruner J. S. Toward a theory of instruction. Cambridge, Cambridge Univ. Press, 1966, 156 p.

35. Gaidar K.M., Malyutina O.P. Features of professional burnout of a higher school teacher in modern conditions. Bulletin of Voronezh State University. Series: Problems of Higher Education, 2016, no. 2, pp. 27-30. (In Russ.)

36. Kunakovskaya L.A. Destructive manifestations in the university teacher professional activity. Teacher of the XXI century, 2016, no. 2, pp. 78-82. (In Russ.)

37. Kunakovskaya L.A., Okhrimenko T. V. Psychological and pedagogical training of employees of «Nanny for an hour» service to interact with preschoolers and primary school children. Proccedings of Voronezh State Pedagogical University, 2014, no. 1, pp. 116-119. (In Russ.)

38. Kunakovskaya L.A. Self-improvement teacher of higher education. Pedagogical Education and science, 2014, no. 6, pp. 89-93. (In Russ.)

39. Kunakovskaya L.A. Professional reflection as a factor in teacher self-improvement. Voronezh, TsNTI, 2015, 204 p. (In Russ.)

40. Anderson T., Varnhagen S., Campbell K. Faculty adoption of teaching and learning technologies: contrasting earlier adopters and mainstream faculty. Canadian Journal of Higher Education, 1998, vol. 28, no. 23, pp. 71-78.

41. Kassymova G.K., Stepanova G.A., Stepanova O.P., Menshikov P.V., Arpentieva M.R., Merezhnikov A.P., Kunakovskaya L.A. Self-development management in educational globalization. International Journal of Education and Information Technologies, 2018, vol. 12, no. 12, pp. 171-176.

42. Klucharev G.A., Dezhina I. G. Russian education for innovative economy: «pressure points». Sociological Studies, 2018, no, 9, pp. 40-48. (In Russ.) DOI: http://dx.doi.org/10.31 857/S013 216250001957-5.

43. Perikova E. I., Atamanova I. V., Bogomaz S. A. Specific features of psychological readiness for innovative activity (with the main focus on young adults in St. Petersburg and Tomsk). Science for Education Today, 2020, vol. 10, no. 1, pp. 62-78. DOI: http://dx.doi.org/10.15293/2658-6762.2001.04.

44. Stock R. M., Von Hippel E., Gillert N. L. Impacts of personality traits on consumer innovation success. Research Policy, 2016, vol. 45, no. 4, pp. 757-769. DOI: https://doi.org/10.1016/j.respol.2015.12.002.

45. Sutanto E.M. The influence of organizational learning capability and organizational creativity on organizational innovation of Universities in East Java, Indonesia. Asia Pacific Management Review, 2017, vol. 22, pp. 128-135. DOI: 10.1016/j.apmrv. 2016.11.002.

46. Tenzer H., Yang P. Personality, values, or attitudes? Individual-level antecedents to creative deviance. International Journal of Innovation Management, 2019, vol. 23, no. 2, pp. 1-30. DOI: http://dx.doi.org/10.1142/S1363919619500099.

47. Walder A.M. Pedagogical innovation in Canadian higher education: professors' perspectives on its effects on teaching and learning. Studies in Educational Evaluation, 2017, vol. 54, pp. 71-82. DOI: 10.1016/j.stueduc.2016.11.001.

48. Weitze C.L. Designing pedagogical innovation for collaborating teacher teams. Journal of Education for Teaching, 2017, vol. 43, no. 3, pp. 361-373. DOI: 10.1080/02607476.2017.1319511.

\section{Информация об авторах}

Арпентьева Мариям Равильевна - доктор психологических наук, доцент, академик Международной академии образования, педагог-психолог Центра психологической, педагогической, медицинской и социальной помощи «Содействие» (Российская Федерация, 248 000, Калуга, ул. Достоевского, 44, e-mail: mariam_rav@mail.ru).

Гайдар Карина Марленовна - доктор психологических наук, доцент, заведующий кафедрой общей и социальной психологии, Воронежский государственный университет (Российская Федерация, 394018, Воронеж, Университетская площадь, 1, e-mail: marlen_lora@mail.ru). 
Кунаковская Людмила Александровна - кандидат педагогических наук, доцент, доцент кафедры педагогики и педагогической психологии, Воронежский государственный университет (Российская Федерация, 394018, Воронеж, Университетская площадь, 1, e-mail: kynludal@mail.ru).

Статья поступила в редакцию 20.04.20

После доработки 28.09.20

Принята к публикации 01.10.20

\section{Information about the authors}

Mariam R.Arpentieva - doctor of psychological sciences, associate professor, academician of the International Academy of Education, teacher-psychologist of the State Treasury Institution of Kaluga Region, Center for Psychological, Pedagogical, Medical and Social Assistance «Assistance» (44 Dostoevsky str., Kaluga, 248 000, Russian Federation, e-mail: mariam_rav@mail.ru).

Karina M. Gaidar - doctor of psychological sciences, associate professor, head of General and Social Psychology Department, Voronezh State University (1 University Square, Voronezh, 394018, Russian Federation, e-mail: marlen_lora@mail.ru).

Ludmila A. Kunakovskaya - candidate of pedagogical sciences, associate professor, associate professor of Pedagogy and Pedagogical Psychology Department, Voronezh State University (1 University Square, Voronezh, 394 018, Russian Federation, e-mail: kynludal@mail.ru).

The paper was submitted 20.04.20

Received after reworking 28.09.20

Accepted for publication 01.10.20 